\title{
BIOFERTILIZACIÓN: EXPERIENCIAS REALIZADAS EN LA PROVINCIA DEL CHACO EN CULTIVOS INTENSIVOS Y EXTENSIVOS
}

\author{
Biofertilization: Intensive and extensive harvest experiences in Chaco
}

\author{
Sotelo, Cristina E. ' ; González, René ${ }^{1}$; Mansilla, Natalia P. ² Soto, María C. ; Balbi, \\ Celsa N. ${ }^{3}$; Pérez, Germán L. ${ }^{1}$ \\ ${ }^{1}$ Instituto Agrotécnico "Pedro M. Fuentes Godo" - FCA-UNNE. ${ }^{2}$ Dirección de Suelos y Agua Rural- \\ Chaco. ${ }^{3}$ Cátedra de Cultivos I - FCA-UNNE. E-mail: cristinasotelo4480@yahoo.com.ar
}

\section{RESUMEN}

La Extensión Rural, como promotora de la innovación, es una herramienta importante para la resolución de problemas asociados a las necesidades de los productores rurales, la pérdida del capital natural y social, o la falta de diversificación de la estructura productiva. En este trabajo se articularon acciones entre el Instituto Agrotécnico, la Dirección de Agricultura, Dirección de Suelos y Agua Rural del Chaco, Instituto de Desarrollo Rural y Agricultura Familiar (IDRAF) y la Dirección de Apoyo Territorial y Agencias de la provincia del Chaco. Para lograr el objetivo se utilizó un método participativo en donde se definieron 3 grandes decisiones: dónde trabajar, con quién trabajar y cómo trabajar con los participantes. La tecnología de biofertilización es una alternativa eficiente en producción sustentable, logrando resultados importantes como promotora de crecimiento vegetal y en el control de fitopatógenos del suelo. Los productores con los que se trabajó en estas experiencias se mostraron abiertos y dispuestos a probar esta tecnología, siendo ellos los que llevaron adelante la inoculación y las distintas mediciones en los ensayos. Ninguno había aplicado biofertilizantes anteriormente, por lo que fue importante la capacitación y el trabajo en conjunto productor-técnico. Es importante seguir generando información de la respuesta de los biofertilizantes en los distintos cultivos regionales, ya que al ser productos biológicos están influenciados con las condiciones ambientales. La difusión de la biofertilización y de los productos que actualmente se encuentran en el mercado es uno de los objetivos compartidos con las distintas instituciones que trabajamos articuladamente en la provincia del Chaco.

Palabras claves: innovación, transferencia de tecnología, inoculación.

\begin{abstract}
Rural Extension fosters innovation which is an important tool for solving problems associated with rural producers' needs, for the loss of natural and social capital and for the lack of productive structure diversification. In this work, actions were articulated among AgroTechnical Institute, Directorate of Agriculture, Chaco Directorate of Rural Soil and Water, Institute of Rural Development and Small-size Family Producers (IDRAF) and Chaco Directorate of Territory Support and Agencies. To achieve the aim, participatory methodology was selected. Three major decisions were made as regards place, participants and working method. Biofertilization technology is an efficient alternative in sustainable production, achieving important results as a plant growth promoter and in soil phytopathogens control. The producers were open-minded and determined to implement this technology at the time of carrying out inoculation and different measurements. None of them had previously applied biofertilizers, so training and working cooperatively between producers and technicians was important. It is crucial to continue researching in the field of biofertilizers in different local crops as biological products are influenced by environmental conditions. Socializing about biofertilization and products that are currently on the market is one of the aims shared by the different institutions that work in Chaco.
\end{abstract}

Key words: innovation, technology transfer, inoculation.

Recibido: 17/jun/2020. Aceptado: 22/jul/2020 
Sotelo, C.E. et al.: Biofertilización en cultivos intensivos y extensivos.

\section{INTRODUCCIÓN}

La Extensión Rural, como promotora de la innovación, es una herramienta importante para la resolución de problemas asociados a las necesidades de los productores rurales, la pérdida del capital natural y social, o la falta de diversificación de la estructura productiva, entre otros (FAO, 2020).

La Extensión Rural es parte de un sistema de innovación donde la articulación y el trabajo conjunto de los actores es la base del éxito y en el que deben jugar un rol protagónico los agricultores y habitantes rurales, y sus organizaciones. Esta articulación aumenta la posibilidad de que las innovaciones sean difundidas, adoptadas y valoradas, y constituyan un aporte. La Extensión Rural debe concebir la innovación como un proceso de aprendizaje donde es vital hacer el enlace entre los nuevos conocimientos y los ya existentes (Báez Lacayo, 2012). Es importante tomar en cuenta los equipos de trabajo interinstitucionales y la formación de extensionistas en estrategias y metodologías que promuevan la innovación. En este trabajo se articularon acciones entre el Instituto Agrotécnico "Pedro Fuentes Godo", la Dirección de Agricultura, Dirección de Suelos y Agua Rural del Chaco, Dirección Apoyo Territorial y Agencias e Instituto de Desarrollo Rural y Agricultura Familiar (IDRAF) de la provincia del Chaco. Desde la experiencia que tienen los técnicos que participaron en el proyecto se pudo detectar un problema común en las distintas producciones agrícolas, que es el deterioro del recurso natural suelo. Hay muchas prácticas para conservar o recuperar suelos degradados. En este caso, la que se investigó junto a los agricultores fue la Biofertilización.

Actualmente para incrementar los rendimientos y calidad en la producción se recurre a diferentes técnicas e insumos como los agroquímicos sintéticos (fertilizantes y pesticidas), sin embargo, su uso excesivo provoca efectos negativos sobre el ambiente. La definición de Biofertilizante (BF) fue cambiando a lo largo de los años como: fertilizantes bacterianos, fitoestimulantes, biopesticidas o bioinoculantes y actualmente el termino más utilizado es biofertilizante (Lira-Saldivar et al., 2013b). Estos son preparados sólidos o líquidos que contienen cepas de células vivas o latentes, que son eficientes para la fijación de nitrógeno, solubilizadores de fosfato o microorganismos celulolíticos, para su aplicación a las semillas o la rizósfera de las plantas, con el objetivo de aumentar el número de esos microorganismos y acelerar los procesos microbianos que aumentan el crecimiento radicular, así como la disponibilidad de nutrientes que pueden ser fácilmente asimilables por las plantas cultivadas (Boraste et al., 2009). La biofertilización no es una técnica nueva, pero está poco difundida y normada, la misma minimiza los impactos del método convencional de producción y asegura la permanencia de la agricultura (Lira Saldivar et al., 2013a; Hernández-Pérez et al., 2017). El empleo de BF microbianos (rizobacterias y hongos formadores de micorrizas), está considerado como una de las contribuciones más importantes de la biotecnología y la microbiología a la agricultura actual. Es una tecnología clave para asegurar la sustentabilidad y productividad agrícola de bajo impacto ambiental, que además de incrementar el rendimiento de los cultivos, mejora la fertilidad del suelo y reduce las poblaciones de microorganismos fitopatógenos, minimizando así los costos de los insumos sintéticos y la contaminación del medio ambiente, coadyuvando de esta manera a la sustentabilidad de la agricultura (Mohammadi y Sohrabi, 2012; Aguado-Santacruz et al., 2012). En términos generales, se puede decir que los biofertilizantes tienen un costo para el productor de sólo $10 \%$ del costo de la fertilización química, y en la mayoría de los casos no debe representar más del 2 a $3 \%$ del costo de producción del cultivo (Grageda Cabrera et al., 2012).

Los biofertilizantes utilizados en este trabajo fueron los que se encuentran disponibles en el mercado Argentino y pueden ser adquiridos por los productores:

1- Trichoderma harzianum: es el enemigo natural de muchos patógenos, entre ellos, los que pertenecen a los géneros Rhyzoctonia, Pythium, Phytophthora, Fusarium, Rhizopus, Botrytis, entre otros. Además, ayuda a reducir los nemátodos, controlando la pudrición de la raíz, marchitamiento y ahogamiento. El mecanismo de acción, al ser aplicado a las raíces, consiste en la formación de una capa protectora, haciendo una simbiosis. El hongo se alimenta de los exudados de las raíces, que son protegidas por él y al mismo tiempo, reduce o elimina las fuentes de alimento del microorganismo patógeno (Schuster y Schmoll, 2010).

2- Azospirillum brasilense: es un género que fija nitrógeno atmosférico y es un importante grupo promotor de crecimiento vegetal (PGPR), ya que el tratamiento con casi todas las cepas y especies de este género afecta positivamente la biomasa y el área superficial de las raíces (Döbereiner et al., 1976; Puente y Perticari, 2006). Pertenecen al grupo de endófitos, diazótrofos facultativos, los cuales pueden colonizar la superficie y el interior 
de las raíces y por lo tanto tienen mejores posibilidades de explotar compuestos carbonados suministrados por las plantas. La producción de fitohormonas es la responsable de causar cambios detectables en la morfología de la raíz, después de la inoculación, lo cual podría estar relacionado a un incremento en la toma de minerales (Okon y Labandera-González, 1994; Russo et al., 2005).

3- Pseudomonas: son otro amplio género bacteriano, en el cual se encuentran especies con potencialidad para ser considerados promotores de crecimiento. Los efectos atribuidos a este grupo bacteriano pueden resumirse en una acción de biocontrol, la secreción de sustancias inductoras y la solubilización de nutrientes. La capacidad de ser agentes de biocontrol (Haas y Défago, 2005), se produce a través de la secreción de antibióticos (pirrolnitrina, pioluteorina), la inducción de resistencia sistémica en la planta y el agotamiento de elementos esenciales para el crecimiento de hongos y bacterias patogénicas, producida por la liberación al medio de pigmentos fluorescentes que actúan como agentes quelantes, cuando estos elementos se tornan escasos en la rizósfera. Por último a las Pseudomonas se les atribuye la capacidad de producir enzimas fosfatasas, ácidos orgánicos (ácido glucónico, cítrico) e inorgánicos (ácido sulfhídrico, nítrico, carbónico) que por medio de la rotura de enlaces y la acidificación del medio, incrementarían la recuperación del fósforo nativo del suelo y la adquisición del aportado por fertilización.

4- Rhizobium: Este grupo de bacterias llamadas rizobacterias promotoras del crecimiento en plantas (PGPR) incluye el género Rhizobium (Sessitsch et al., 2002). Estas bacterias se caracterizan por su habilidad de facilitar directa o indirectamente el desarrollo de la raíz y del follaje de las plantas. La estimulación directa puede incluir la fijación de nitrógeno (Sessitsch et al., 2002), la producción de hormonas (Perrine et al., 2004), de enzimas (Mayak et al., 2004) de sideróforos (Carson et al., 2000) y solubilización de fosfatos (Rodriguez y Fraga, 1999).

5- Bacillus: Una gran diversidad de especies del género Bacillus han demostrado tener actividad antagónica contra diversos microorganismos fitopatógenos de cultivos agrícolas, tales como maíz, arroz, frutales, entre otros (Wang et al., 2014; Li et al., 2015). El estudio de esta capacidad de Bacillus se inició por el descubrimiento de la actividad insecticida de las proteínas Cry producidas por B. thuringiensis; en la actualidad diversas especies del género Bacillus (B. subtilis, B. pumilus, B. amyloliquefaciens y B. licheniformis) son ampliamente estudiadas para mitigar la incidencia de enfermedades de importancia agrícola (Raaijmakers y Mazzola, 2012). Dentro de los bioplaguicidas microbianos disponibles comercialmente, Bacillus es el género más explotado en la biotecnología agrícola, con un $85 \%$ de los productos bacterianos, debido a su gran versatilidad metabólica que le permiten llevar a cabo el control biológico de plagas y enfermedades por diversos mecanismos. Además, este género bacteriano es capaz de producir endosporas, siendo éstas el principal ingrediente activo de los formulados, confiriéndole una mayor viabilidad en el tiempo (Ongena y Jaques, 2008).

6- Bioestimulante (Biosmart) a base de metabolitos de la fermentación de microorganismos. Un Bioestimulante es una sustancia y/o microorganismo cuya función una vez aplicado es estimular los procesos naturales de la planta.

El objetivo de este trabajo fue dar a conocer y difundir la técnica de biofertilización con los productos que actualmente se encuentran en el mercado, y evaluar junto a los productores los resultados en condiciones ambientales locales.

\section{METODOLOGÍA Y RESULTADOS OBTENIDOS}

Para lograr el objetivo se utilizó un método participativo (Bellon, 2002) en donde se definieron 3 grandes decisiones: dónde trabajar (en otras palabras, seleccionar un sitio), con quién trabajar (quién debe participar) y cómo trabajar con los participantes. Estas decisiones son críticas porque los técnicos dependerán de las personas seleccionadas para que les proporcionen información — tanto de los problemas, recursos y limitaciones, como de las condiciones locales-y los ayuden a realizar los experimentos. La selección del sitio del trabajo de campo define en gran medida las comparaciones y lecciones que se obtienen, y de ella depende si dichas comparaciones y lecciones son para aplicarse en la localidad o si pueden generalizarse a otras regiones o condiciones. Los agricultores y sus familias no son homogéneos, aun cuando formen parte de la misma comunidad.

La técnica de investigación participativa (Bellon, 2002) cuenta con tres pasos: 
Sotelo, C.E. et al.: Biofertilización en cultivos intensivos y extensivos.

1-Selección del lugar: El primer paso para decidir con cuáles agricultores trabajar es decidir dónde trabajar. Junto con las demás instituciones participantes, se eligieron los lugares donde realizar las experiencias. Con la Dirección de Agricultura e IDRAF se eligieron productores frutihortícolas del cinturón verde del gran Resistencia y con la Dirección de Suelos y Agua Rural y la Dirección de Apoyo Territorial y Agencias se eligieron productores agrícolas del dorsal agrícola del Chaco. Se eligieron estos sitios porque son los lugares de los polos agrícolas y donde los técnicos tienen mayor frecuencia de visitas. Esto permitió aumentar al máximo la posibilidad de hacer comparaciones significativas, basadas en algunos factores exógenos clave que en teoría influyen en las condiciones y/o decisiones de los agricultores.

2. Selección de los experimentadores: En la investigación participativa se trabaja con experimentadores que son agricultores con quienes los técnicos realizan experimentos y evaluaciones. La elección se basó en criterios bien definidos y preestablecidos:

- Agricultores que son conocidos por su curiosidad intelectual y están abiertos a nuevas tecnologías.

- Agricultores que se comprometen a cuidar y tomar datos del ensayo.

- Agricultores que son asesorados por las instituciones participantes.

3. Definir cómo interactuar: Una vez identificados los productores, se llevaron a cabo intercambios individuales que consisten en una interacción entre los técnicos y el productor. Allí se organizó la planificación de las actividades junto a productores ubicados en distintas localidades y se decidió que biofertilizante probar de acuerdo al interés y las necesidades de cada productor.

Se realizaron ensayos de aplicaciones de biofertilizantes en distintos cultivos, tanto a nivel extensivo como intensivo y se evaluaron sus efectos a través de medidas cuantitativas de crecimiento del cultivo. En algunos ensayos se comparó la biofertilización con la aplicación de fertilizantes sintéticos. Los ensayos se llevaron adelante junto al productor y las instituciones intervinientes. Se realizaron visitas periódicas para dar seguimiento y se registraron las características de cada cultivo.

\section{1- Cultivo de Algodón}

Los técnicos del Inst. Agrotécnico, Dirección de Suelo y Agua Rural y Dirección Apoyo Territorial y Agencias visitaron a tres productores de algodón del sudoeste del Chaco, los cuales estaban trabajando con asesoramiento en la aplicación de distintas tecnologías para mejorar los rendimientos del cultivo. En esta ocasión se les propuso trabajar con biofertilización en el cultivo de algodón (Figura 1). La experiencia resultó de mucho interés para los productores, que pudieron ver otras opciones aparte de los fertilizantes de síntesis química que habitualmente utilizan. Se realizaron inoculaciones (Figura 2) en la siembra con los promotores de crecimiento Pseudomonas, Azospirillum y Rhizobium y el bioestimulante (Biosmart).

Los tratamientos se realizaron en franjas de 10 lineos de $1000 \mathrm{~m}$ de largo, al momento de cosecha se muestrearon 20 plantas por franja. Se llevaron las plantas al laboratorio del Instituto Agrotécnico y se realizó el desmote manual. Con los resultados de peso de fibra por planta se estimó el rendimiento potencial por ha. Los resultados en el rendimiento de fibra solo se obtuvieron en un campo, ya que ese año la zona sufrió severas inundaciones lo que produjo pérdidas totales del cultivo. Los resultados se pueden observar en la Figura 3.

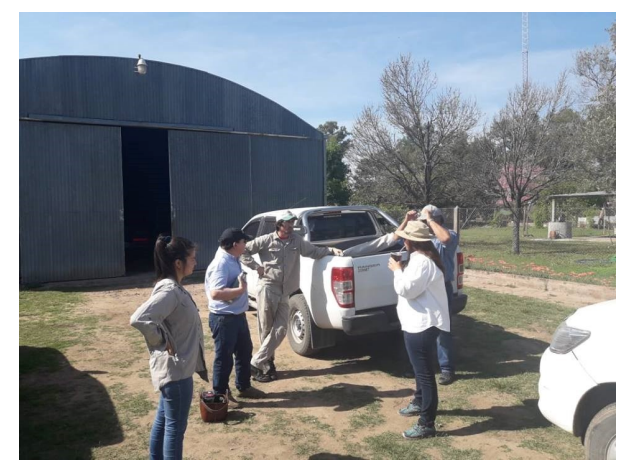

Figura 1. Explicando y coordinando tareas con el productor.

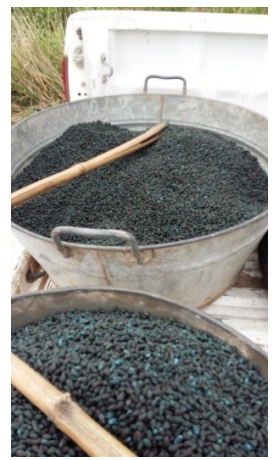

Figura 2. Inoculación de semillas de algodón con bioestimulante. 


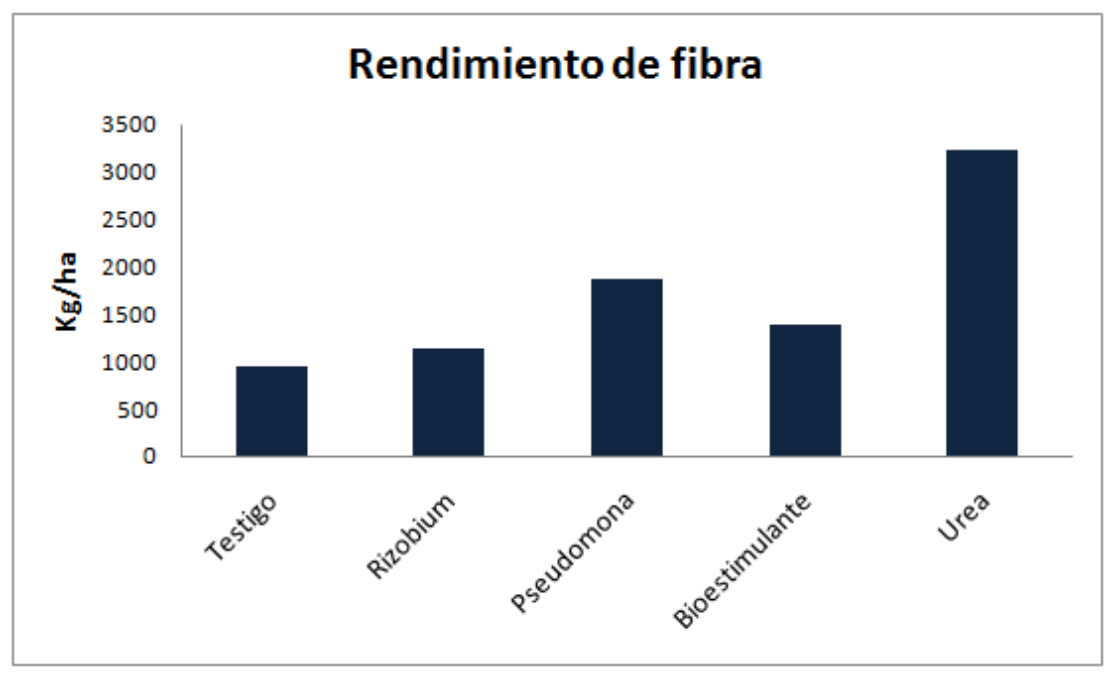

Figura 3. Rendimiento de fibra ( $\mathrm{kg} / \mathrm{ha})$ de algodón en los distintos tratamientos.

Al finalizar el ensayo se mostraron los resultados al productor y se intercambiaron opiniones sobre el efecto de la biofertilización. El productor expresó que las franjas inoculadas estaban más verdes y vigorosas que el testigo. Los datos obtenidos de rendimiento potencial mostraron una tendencia positiva a favor de las franjas biofertilizadas. Así mismo, el tratamiento fertilizado fue el que dio mejores rendimientos, teniendo que evaluar en otras condiciones climáticas (el cultivo se encontró sometido a semanas de anegamiento por inundaciones atípicas en el período de implantación) y realizar análisis estadísticos para corroborar estos datos. La importancia de este ensayo fue que despertó el interés y la predisposición de los productores en la utilización de productos de origen biológico. Los productores se comprometieron a continuar trabajando junto al equipo, explorando alternativas agroecológicas para la producción de cultivos extensivos.

\section{2- Cultivo de mandioca}

Otra experiencia realizada con los productores, Instituto de Desarrollo Rural y Agricultura Familiar (IDRAF) y la Dirección de Producción Agrícola de la Provincia del Chaco fue en la localidad de La Leonesa. El IDRAF impulsa la técnica de producción de plantines de mandioca en vivero, esta técnica consiste en plantar estacas en macetas y después de dos meses realizar el transplante a campo. Para difundir esta técnica se realizó una jornada de campo donde el Instituto Agrotécnico expuso distintas maneras de aportar materia orgánica al suelo y la técnica de biofertilización (Figura 4). En lo referido a esta última temática se comentó a los productores sobre lo que es la biofertilización, los distintos tipos de microorganismos utilizados y se les propuso realizar un ensayo (Figura 5).

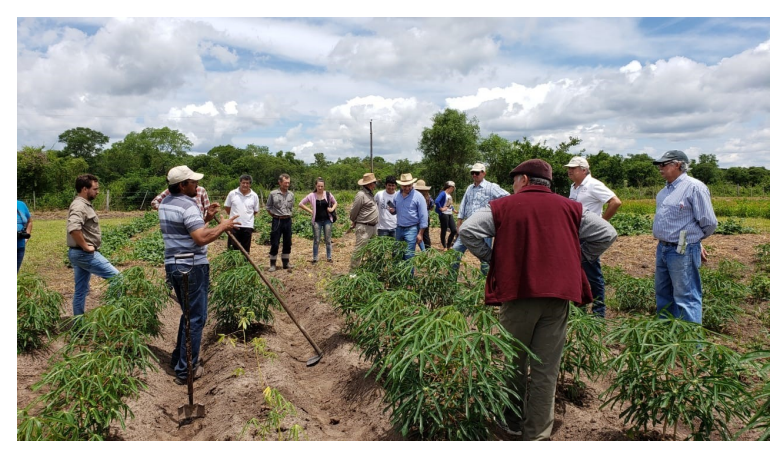

Figura 4. Productores y técnico del IDRAF cuentan cómo se realizó la plantación.

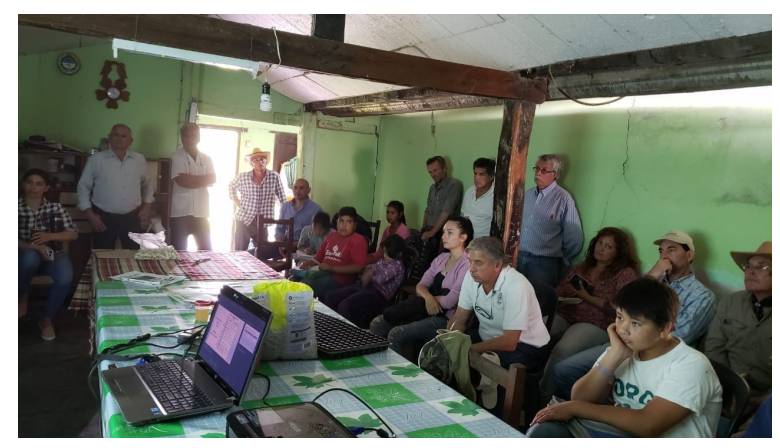

Figura 5. Técnicos del Instituto Agrotécnico, Dirección de producción Agrícola y el IDRAF realizan una exposición de diversos temas útiles para la producción hortícola. 


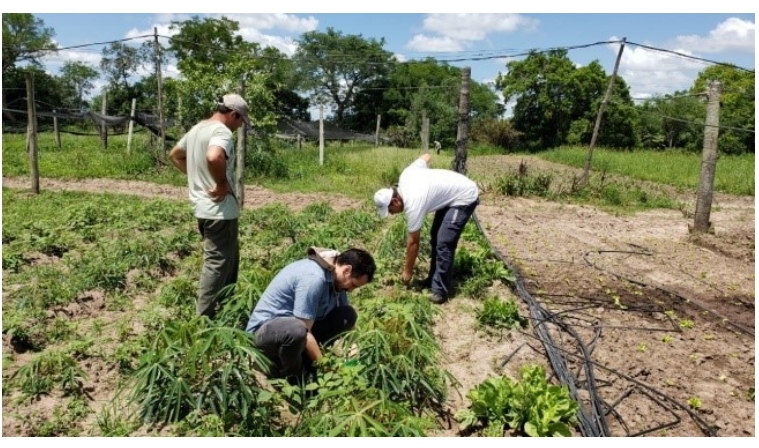

Figura 6. Técnicos del Instituto Agrotécnico y del IDRAF junto al productor realizan el ensayo de biofertilización.

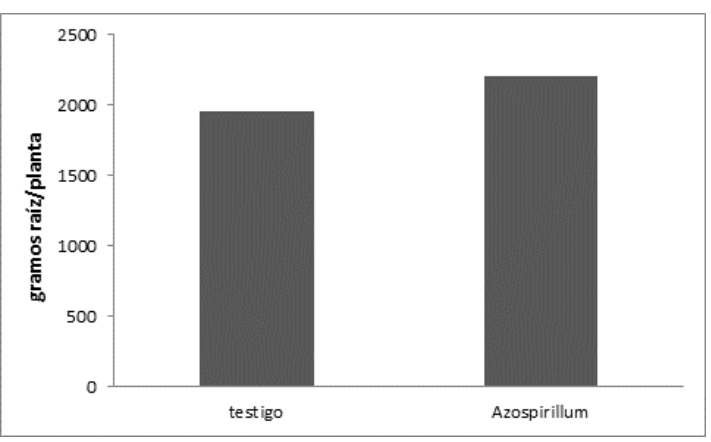

Figura 7. Rendimiento del cultivo de mandioca en los distintos tratamientos (gramos de raíz /planta).

En el campo del productor demostrador se realizó el ensayo cuando las plantas de mandioca tenían $10 \mathrm{~cm}$ de alto en promedio (Figura 6). Se inoculó al costado de la planta con el biofertilizante Azospirillum, cada parcela fue de $40 \mathrm{~m}^{2}$, los tratamientos fueron inoculadas y sin inocular. El productor cosechó por separado cada parcela, contó el número de plantas y peso las raíces de cada una. Los resultados podemos observar en la Figura 7 siendo el tratamiento inoculado el que presentó mayor rendimiento.

\section{3-Cultivo de mamón}

Este ensayo se realizó con la empresa "Isla del Cerrito" y la dirección de Agricultura del Chaco. Se realizaron cuatro tratamientos con 30 repeticiones en la siembra del cultivo en invernáculo (Figuras 8 y 9). Los mismos fueron: 1. Testigo (T); 2. Azospirillum (Az); 3. Trichoderma (Tr); 4. Azospirillum + Trichoderma (Az+Tr).

Se midió número de hojas, 50 días después de la siembra. Para el análisis estadístico se utilizó InfoStat 2016 y se aplicó un análisis de varianza y test de Tukey $\mathrm{p} \leq 0,05$. En la variable sobrevivencia se realizó un análisis descriptivo calculando el porcentaje para cada tratamiento. Los resultados (Figura 10) arrojaron que el tratamiento coinoculado (4) desarrolló más hojas. Este tratamiento también fue el que mayor porcentaje de sobrevivencia presentó a los 81 días (Figura 11). A raíz de este ensayo la empresa evaluó reemplazar el fungicida que utilizaba en semillas por los biofertilizantes ensayados.
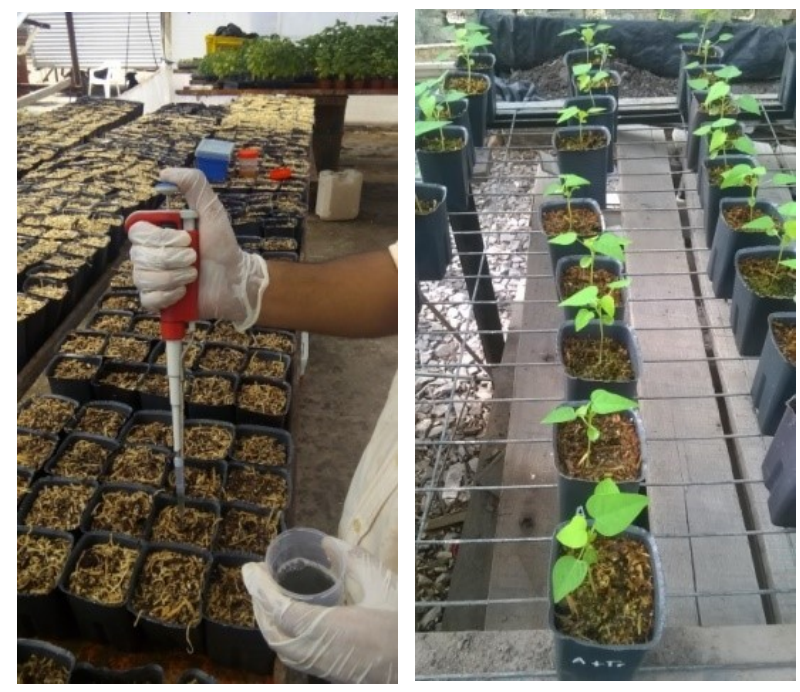

Figuras 8 y 9. Inoculación de tratamientos en mamón con la aplicación de inoculantes $T$. harzianum, A. brasilense y con la aplicación funguicida (Izquierda). Plantines al mes de la siembra (derecha).

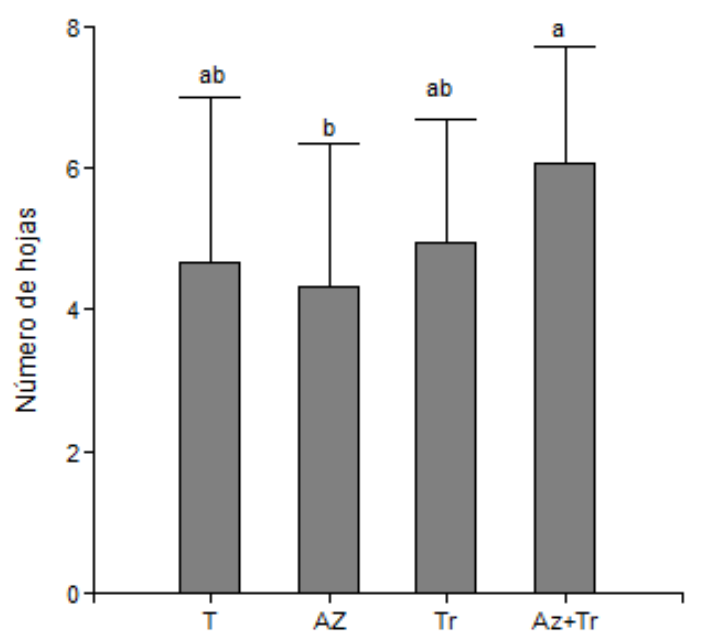

Figura 10. $\mathrm{N}^{\circ}$ de hojas tomados a los 50 dds (días después siembra). $\mathrm{T}=$ testigo; $\mathrm{Az}=$ inoculado con Azospirillum brasilense; $\mathrm{Tr}=$ Trichoderma harzianum; $\mathrm{Az}+\mathrm{Tr}=$ Azospirillum brasilense+ Trichoderma harzianum (letras distintas difieren estadisticamente $p \leq 0,05)$. 


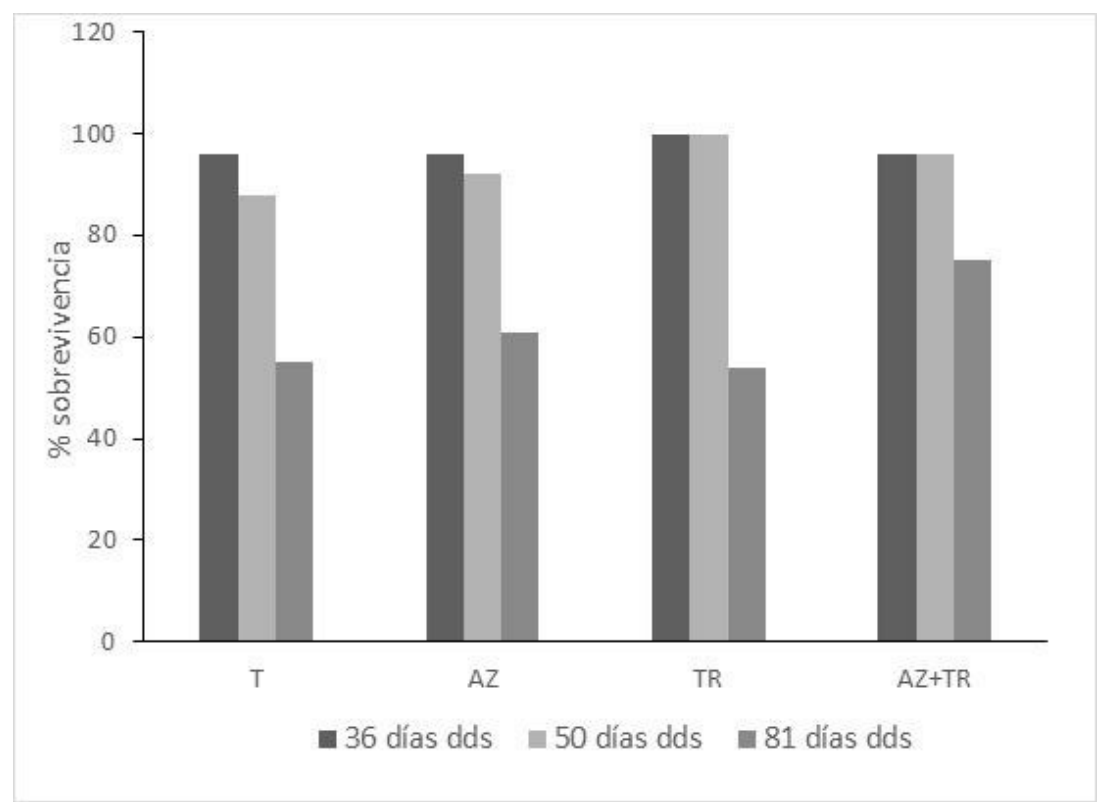

Figura 11. Porcentaje de sobrevivencia a los 36, 50 y 81 dds (días después siembra). T=testigo; Az =inoculado con Azospirillum brasilense; $\mathrm{Tr}=$ Trichoderma harzianum; $\mathrm{Az}+\mathrm{Tr}=$ Azospirillum brasilense + Trichoderma harzianum.

\section{4- Cultivo de Tabaco}

El lugar donde se realizó la experiencia fue en el campo de un productor de la localidad de Margarita Belén (Chaco). Productor asesorado de la Dirección de Agricultura. Las semillas de tabaco, Nicotiana tabacum, son de la variedad Virginia 394, pelleteadas. La siembra se realizó de forma manual, utilizando sustrato esterilizado, con perlita para asegurar un drenaje adecuado. Luego se llenaron de agua las bandejas hasta su flotación.

Los biofertilizantes que se han utilizado fueron: Trichoderma hariazanum, Bacillus subtilus y Azospirillum brasilense que se compararon con un tratamiento testigo.

$A$ partir de cada uno de los inoculantes se prepararon las diluciones adecuadas. La inoculación se realizó luego de la siembra en cada semilla de las bandejas, y su sustrato adyacente, por medio de micropipetas. Se realizó una bandeja por tratamiento (Figura 12).

Al mes se realizó la medición de las plantas emergidas (Figura 13). Todos los tratamientos tuvieron mejor emergencia de plántulas con respecto al testigo. Este fue un resultado alentador, ya que uno de los mayores problemas en la producción tabacalera, es que se deben utilizar varios fungicidas para evitar el damping off.

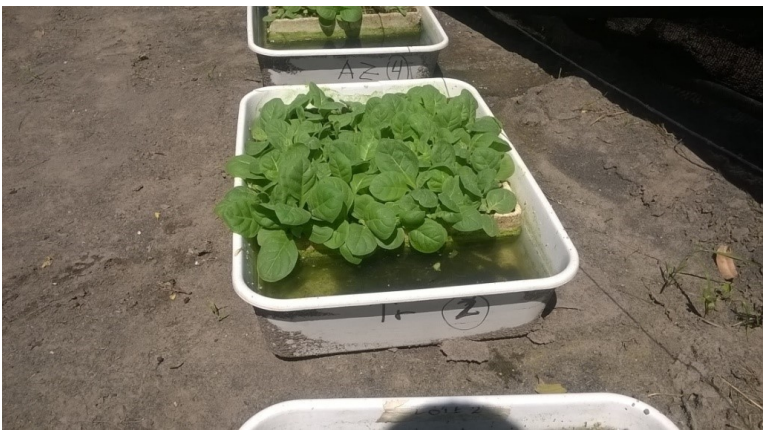

Figura 12. Tratamiento de T. harzianum en tabaco (Productor de Margarita Belén).

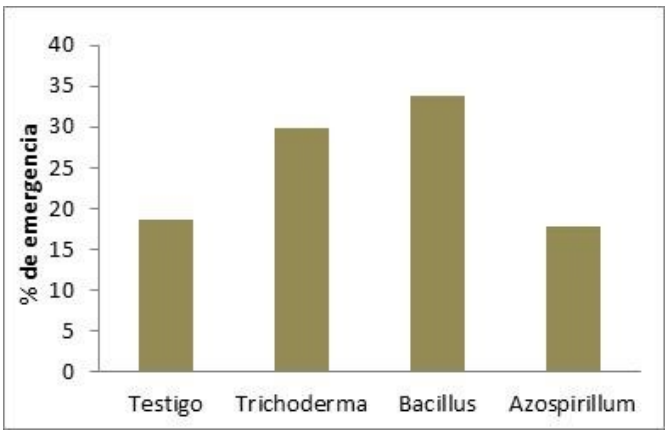

Figura 13. Porcentaje de emergencia en los distintos tratamientos con biofertilizantes. 
Sotelo, C.E. et al.: Biofertilización en cultivos intensivos y extensivos.

\section{CONSIDERACIONES FINALES}

La tecnología de biofertilización es una alternativa eficiente para una producción sustentable, logrando resultados importantes como promotora de crecimiento vegetal y mejorando la supervivencia de los cultivos en las etapas iniciales. A nivel zonal los productos no son muy conocidos, así como se desconoce su efecto sobre la producción en las condiciones climáticas de la región.

Los productores con los que se trabajó en estas experiencias se mostraron abiertos y dispuestos a probar esta tecnología, siendo ellos los que llevaron adelante la inoculación y el seguimiento de los ensayos. Ninguno había aplicado biofertilizantes anteriormente, por lo que fue importante la capacitación y el trabajo en conjunto productor-técnico.

Es importante seguir generando información de la respuesta de los biofertilizantes en los distintos cultivos regionales, ya que al ser productos biológicos están influenciados por las condiciones ambientales.

La articulación entre las diferentes instituciones permitió la difusión de la técnica de biofertilización y llegar a objetivos comunes en el marco de la producción sustentable.

\section{AGRADECIMIENTOS}

A los productores Damián Godoy, David Valihora, Mauricio Mencari y Luis Zago, por abrirnos las tranqueras de sus campos y por la predisposición en la aplicación de nuevas tecnologías.

Colaboradores de los proyectos: Silva Luis; Kulay Jorge; Galeano Emiliano; Pokorasky Luciano; Bosch Jacinto; Risso Patron Gastón; Kosciak Rubén.

\section{BIBLIOGRAFÍA}

Aguado-Santacruz, G.A., Moreno-Gómez, B., Jiménez-Francisco, B., García-Moya, E. y Preciado-Ortiz, R.E. (2012). Impacto de los sideróforos microbianos y fitosidéforos en la asimilación de hierro por las plantas: una síntesis. Revista fitotecnia mexicana, 35(1): 9-21.

Báez Lacayo, L. (2012). Extensión Rural como parte de un Sistema de Innovación. RELASER - Red Latinoamericana para Servicios de Extensión Rural Rimisp - Centro Latinoamericano para el Desarrollo Rural Santiago, Chile. (C) Rimisp-Centro Latinoamericano para el Desarrollo Rural.

Bellon, M.R. (2002). Métodos de investigación participativa para evaluar tecnologías: manual para científicos que trabajan con agricultores. CIMMYT.

Boraste, A., Vamsi, K.K., Jhadav, A., Khairnar, Y., Gupta, N., Trivedi, S., Joshi, B. (2009). Biofertilizers: A novel tool for agriculture. International Journal of Microbiology Research, 1(2): 23-31. http:// dx.doi.org/10.9735/0975-5276.1.2.23-31

Carson, K.C., Meyer, J.M. y Dilworth, M. (2000). Hydroxamate siderophores of root nodule bacteria. Soil Biology \& Biochemistry 32: 11-21. https://doi.org/10.1016/S0038-0717(99)00107-8

Döbereiner, J., Marriel, I. y Nery, M. (1976). Ecological distribution of Spirillum lipoferum Beijerinck. Can J Microbiol 22: 1464-1473. https://cdnsciencepub.com/doi/10.1139/m76-217

FAO. (2020). La Extensión Rural y su rol como promotora de los procesos. www.fao.org > family-farming. (Último acceso 02/06/2020)

Grageda Cabrera, O. A., Díaz-Franco, A., Peña Cabriales, J. J., Vera Nuñez, J. A. (2012). Impacto de los biofertilizantes en la agricultura. Rev. Mex. Cienc. Agríc vol.3 (6): 1261-1274. https:// doi.org/10.29312/remexca.v3i6.1376

Haas, D. y Défago, G. (2005). Biological control of soil-borne pathogens by fluorescent pseudomonads. Nat Rev Microbiol 3: 307-319. https://doi.org/10.1038/nrmicro1129

Hernández Pérez, A., Valdés-Aguilar, L.A., Cárdenas-Flores, A., Ibarra-Jiménez, L., MéndezArguello, B., Vera-Reyes, I. y Lira-Saldivar, R.H. (2017). Photosynthesis, growth and yield of Solanum lycopersicum as influenced by the use of microbial biofertilizers. Agrochimica 61 (2): 95-109.

Li, Y, Gu, Y, Li, J, Xu, M, Wei, Q y Wang, Y. (2015). Biocontrol agent Bacillus amyloliquefaciens LJ02 induces systemic resistance against cucurbits powdery mildew. Front Microbiol 6:883. http:// dx.doi.org/10.3389/fmicb.2015.00883. 
Lira-Saldivar, R.H., Tucuch-Pérez, M.A., López-López, D., Borjas-Banda, C.L. (2013a). Respuesta del chile habanero (Capsicum chinense Jacq.) a la biofertilización y acolchado plástico en producción orgánica. Agricultura Sostenible 9: 538-552.

Lira-Saldivar, R.H., Vázquez-Santiago, E., Valdez-Aguilar, L.A., Cárdenas-Flores, A., Ibarra Jiménez, L. y Hernández-Suárez, M. (2013b). Producción orgánica de pepino (Cucumis sativus L.) en casasombra con biofertilizantes y acolchado plástico. Agricultura Sostenible. 9: 802-815.

Mayak, S., Tirosh, T. y Glick, B. (2004). Plant growth-promoting bacteria confer resistance in tomato plants to salt stress. Plant Physiology and Biochemistry. 42: 565-572. https://doi.org/10.1016/ j.plaphy.2004.05.009

Mohammadi K., y Sohrabi, Y. (2012). Bacterial biofertilizers for sustainable crop production: a review. ARPN J Agric Biol Sci, 7(5), 307-316.

Okon, Y. y Labandera-Gonzalez, C. (1994). Agronomic applications of Azospirillum: An evaluation of 20 years worlwide field inoculation. Soil Biol. Biochem. Vol 26 (12):1591-1601.

Ongena, M. y Jacques, P. (2008). Bacillus lipopeptides: versatile weapons for plant disease biocontrol. Trends Microbiolgy. 16:115-125. http://dx.doi.org/10.1016/j.tim.2007.12.009

Perrine, F., Rolfe, B., Hynes, M. y Hocart, C. (2004). Gas chromatography-mass spectrometry analysis of indolacetic acid and tryptophan following aquerous chloroformate derivatisation of Rhizobium exudates. Plant Physiology and Biochemistry. 42: 723-729.

Puente, M. y Perticari, A. (2006). Inoculación de trigo con Azospirillum. Trigo en Siembra Directa. Revista Técnica de la Asociación Argentina de Productores en Siembra Directa, AAPRESID. 97-99.

Raaijmakers. J.M. y Mazzola, M. (2012). Diversity and Natural Functions of Antibiotics Produced by Beneficial and Plant Pathogenic Bacteria. Annual Reviews of Phytopathology. 50:403-424. http:// dx.doi.org/10.1146/annurev-phyto-081211-172908.

Rodriguez, H. y Fraga, R. (1999). Phosphate solubilizing bacteria and their role in plant growth promotion. Biotechnology Advances. 17: 319-339. https://doi.org/10.1016/S0734-9750(99)00014-2

Russo, A., Felici, C., Toffanin, A., Götz, M., Collados, C., Barea, J.M., Moënne-Loccoz, Y., Smalla, K., Vanderleyden, J. y Nuti, M. (2005). Effect of Azospirillum inoculants on arbuscular mycorrhiza establishment in wheat and maize plants. Biol Fertil Soils 41:301-309. https://doi.org/10.1007/s00374005-0854-7

Schuster, A., Schmoll, M. (2010). Biology and biotechnology of Trichoderma . Appl Microbiol Biotechnol 87: 787-799. https://doi.org/10.1007/s00253-010-2632-1

Sessitsch, J., Howieson, X., Perret, H., Antoun, H. y Martinez-Romero, E. (2002). Advances in Rhizobium Research. Critical Reviews in Plant Sciences. 21 (4): 323-378. https://doi.org/10.1080/0735260291044278

Wang, X., Wang, L., Wang, J., Jin, P., Liu, H. y Zheng, Y. (2014). Bacillus cereus AR156-Induced Resistance to Colletotrichum acutatum is Associated with Priming of Defense Responses in Loquat Fruit. PLos ONE. 9(11):e112494. http://dx.doi.org/10.1371/journal.pone.0112494. 